\title{
Efficacy of Fungicide Applications During and After Anthesis Against Fusarium Head Blight and Deoxynivalenol in Soft Red Winter Wheat
}

D. L. D'Angelo, Department of Plant Pathology, The Ohio State University, Ohio Agricultural Research and Development Center, Wooster, OH 44691; C. A. Bradley and K. A. Ames, Department of Crop Sciences, University of Illinois, Urbana, IL 61801; and K. T. Willyerd, L. V. Madden, and P. A. Paul, Department of Plant Pathology, The Ohio State University, Ohio Agricultural Research and Development Center, Wooster, OH 44691

\begin{abstract}
D’ Angelo, D. L., Bradley, C. A., Ames, K. A., Willyerd, K. T., Madden, L. V., and Paul, P. A. 2014. Efficacy of fungicide applications during and after anthesis against Fusarium head blight and deoxynivalenol in soft red winter wheat. Plant Dis. 98:1387-1397.

Seven field experiments were conducted in Ohio and Illinois between 2011 and 2013 to evaluate postanthesis applications of prothioconazole + tebuconazole and metconazole for Fusarium head blight and deoxynivalenol (DON) control in soft red winter wheat. Treatments consisted of an untreated check and fungicide applications made at early anthesis $(\mathrm{A}), 2(\mathrm{~A}+2), 4(\mathrm{~A}+4), 5(\mathrm{~A}+5)$, or $6(\mathrm{~A}+6)$ days after anthesis. Six of the seven experiments were augmented with artificial Fusarium graminearum inoculum, and the other was naturally infected. FHB index (IND), Fusarium damaged kernels (FDK), and DON concentration of grain were quantified. All application timings led to significantly lower mean arcsine-square-root-transformed IND and

untreated check; however, arcIND, arcFDK, and $\log \mathrm{DON}$ for the postanthesis applications were generally not significantly different from those for the anthesis applications. Relative to the check, A+2 resulted in the highest percent control for both IND and DON, 69 and 54\%, respectively, followed by $\mathrm{A}+4$ (62 and 52\%), A+6 (62 and 48\%), and $\mathrm{A}$ (56 and $50 \%$ ). A+2 and A+6 significantly reduced IND by 30 and $14 \%$, respectively, relative to the anthesis application. Postanthesis applications did not, however, reduce DON relative to the anthesis application. These results suggest that applications made up to 6 days following anthesis may be just as effective as, and sometimes more effective than, anthesis applications at reducing FHB and DON.
\end{abstract} FDK (arcIND and arcFDK) and log-transformed (logDON) than in the
Fusarium head blight (FHB), commonly known as scab, is a fungal disease caused by Fusarium graminearum and other related species (26) that affect small grain crops such as wheat, barley, and rye in many regions around the world. FHB causes significant losses in grain yield and quality due to floret sterility, production of small, shriveled light-weight kernels, and contamination of grain with mycotoxins, especially deoxynivalenol (DON). FHB development is often positively correlated with DON contamination (31). Cultivation of FHB-affected seeds may lead to poor stand establishment as a result of reduced seed vigor and germination, and seedling blight (15). In addition, FHB is a concern for the milling and baking industries as it affects the quality of the flour produced from infected grain (11). It may also have negative effects on animal health, especially nonruminant animals, if mycotoxin-contaminated grain is consumed (12).

Efforts to manage FHB and DON are most effective when cultural practices such as rotation with nonhost crops and tillage are employed along with genetic resistance and a well-timed fungicide application (37,39). Lori et al. (22) suggested that although cultural practices alone may be effective at reducing in-field inoculum and FHB severity, under favorable weather conditions, an integrated management approach that includes an accurate prediction model and timely use of a fungicide is necessary to effectively manage FHB. The use of such a model is now an integral part of FHB management programs in the United States, providing estimates of disease risk in 30 states to help guide fungicide application $(9,33)$. Usually only a single anthesis application is justified, as the cost of additional treatments is rarely offset by increased yield in U.S. wheat production systems (24). Results from multiple years of

Corresponding author: P. A. Paul, E-mail: paul.661@ @su.edu

Accepted for publication 16 April 2014.

http://dx.doi.org/10.1094/PDIS-01-14-0091-RE

(C) 2014 The American Phytopathological Society
FHB management experiments showed that, depending on the level of disease and susceptibility of the cultivar being treated, a welltimed application of prothioconazole (Proline 480 SC; Bayer CropScience, Research Triangle Park, NC), tebuconazole + prothioconazole (Prosaro 421 SC; Bayer CropScience), or metconazole (Caramba 90 SL; BASF Corporation Agricultural Products, Research Triangle Park, NC) provided between 40 and $70 \%$ reduction of FHB and DON $(29,30,39)$.

High relative humidity, rainfall, and surface wetness during anthesis and early grain fill, the period of greatest host susceptibility to infection, are environmental risk factors for FHB development and DON contamination. These are the conditions required for spore production (13), dissemination $(27,35)$, and infection of the wheat spike (2). Consequently, fungicide application for FHB management is especially emphasized when anthesis coincides with wet weather $(3,17)$. However, under wet field conditions, when fungicides are most warranted, current recommendations may be difficult to implement due to physical limitations of spraying a fungicide in the rain and driving equipment through wet fields. These limitations have led to questions being asked about the benefit of pre- and postanthesis fungicide application for FHB and DON management. Edwards and Godley (14) evaluated the effects of preanthesis application of prothioconazole (Proline $480 \mathrm{SC}$; Bayer CropScience) on FHB and DON in winter wheat in the United Kingdom, and reported that applications made at Zadoks GS31 (Feekes GS 6, stem elongation), GS39 (Feekes GS 9, full flag leaf emergence), and GS65 (Feekes GS 10.5.2, midanthesis) reduced FHB incidence and DON by 50, 58, and 83\%, and 27, 49, and $57 \%$, respectively, relative to the untreated check. Applications made at all three growth stages provided $97 \%$ control of FHB incidence and $83 \%$ control DON. Based on results from a similar study conducted in Canada in which tebuconazole (Folicur 3.6 F; Bayer CropScience) was applied to hard red spring wheat at GS39 and GS60 (Feekes 10.5.1, early anthesis), Wiersma and Motteberg (38) also reported that, across several cultivars, the best application timing for FHB control (as well as foliar diseases) was at early anthesis, but concluded that FHB levels were too low to adequately 
compare treatments. Evaluating the effects of postanthesis fungicide applications on FHB, DON, and nivalenol (NIV) in artificially inoculated field experiments, Yoshida et al. (41) observed that an anthesis application of thiophanate-methyl (Topsin M; Nippon Soda Co. Ltd., Chiyodaku, Tokyo) resulted in significantly lower levels of FHB than the untreated check and applications made at 10, 20, and 30 days after anthesis (DAA). However, in one of the two years of the study, they observed that a single application at 20 DAA or an application made at anthesis followed by a second at 20 DAA significantly reduced mycotoxin contamination (DON + NIV) relative to the check and the anthesis application, without reducing FHB severity. This led them to speculate that late-milk (GS 11.1) was probably the best time to apply a fungicide for mycotoxin control in wheat, since toxins may continue to accumulate during grain development.

It is clear from the studies cited above that pre- and postanthesis fungicide applications may contribute to FHB and DON reduction, but the anthesis applications still stood out as being the most effective for FHB in all cases. However, tebuconazole + prothioconazole and metconazole, the two most effective fungicides against FHB (30), were not evaluated in any of the aforementioned studies. In addition, none of the studies were conducted in soft red winter wheat production regions of the United States. Given that fungicide effects on FHB and DON have been shown to vary considerably among active ingredients, locations, and wheat market classes (30), further research is needed to determine whether applications made after anthesis will provide adequate control of this disease and its associated toxins in soft red winter wheat under field conditions in the U.S. Midwest. If foliar fungicides are still able to adequately control FHB and DON when applied after anthesis, recommended application times could potentially be extended, allowing producers the flexibility of making applications after rain events. The objectives of this research were to: (i) determine the effect of postanthesis applications of tebuconazole + prothioconazole and metconazole on FHB and DON in soft red winter wheat under different naturally infected and artificial inoculum augmented field conditions, (ii) determine whether the magnitude of FHB and DON responses to postanthesis fungicide applications vary with active ingredient, cultivar, and baseline disease and toxin levels, and (iii) estimate the efficacy (based on mean percent control of FHB index and DON) of postanthesis fungicide applications relative to untreated and anthesis reference treatments.

\section{Materials and Methods}

Plot establishment and experimental design. Wooster, $\mathrm{OH}$. Experiments were conducted during the 2011 (WO11), 2012 (WO12), and 2013 (WO13) wheat growing seasons on the Snyder Farm at the Ohio Agricultural Research and Development Center (OARDC) near Wooster. On 8 October 2010 and 7 October 2011, FHB moderately resistant and susceptible soft red winter wheat (SRWW) cultivars, Malabar and Hopewell, respectively, were planted in $1.5 \times 6 \mathrm{~m}$ plots, with 1.5 -m border rows of the cultivar Truman planted between adjacent plots to minimize interplot interference. Both Malabar and Hopewell are midseason cultivars in terms of their maturity. Seeds were planted using a Kincaid planter at a seeding rate of $4 \times 10^{6}$ seeds/ha.

In 2011, the experimental design was a randomized complete block, with three replicate blocks and a split-split-plot arrangement of cultivar as whole plot, fungicide application timing as subplot, and inoculum density as the sub-sub-plot. In 2012, a similar experimental design and the same three treatment factors were used; however, they were arranged differently. Inoculum density was the whole plot, fungicide timing the subplot, and cultivar the sub-subplot.

For the experiment conducted in 2013, plots were established on 25 September 2012. However, only the susceptible cultivar Hopewell was planted as described above. The experimental design was also a split-split-plot, with three replicate blocks. Inoculum density was the whole plot, fungicide active ingredient the subplot, and application timing the sub-sub-plot.
South Charleston, OH. During the 2011 (SC11) and 2013 (SC13) growing seasons, similar experiments to those conducted in Wooster were conducted at the OARDC Western Agricultural Research Station, near South Charleston, $220 \mathrm{~km}$ southwest of Wooster. On 8 October 2010 and 13 October 2012, the FHB-susceptible, early-maturing SRWW cultivar Bravo was planted in $3 \times$ $6 \mathrm{~m}$ plots at a seeding rate of $3 \times 10^{6}$ seeds/ha, with $3-\mathrm{m}$ border strips between adjacent plots. In 2011, the experimental design was a randomized complete block, with four replicate blocks of seven treatments. Treatments consisted of a factorial arrangement of two different fungicides and application at three different growth stages (Table 1), plus an untreated check. This study was naturally infected. In 2013, the experimental design was a randomized complete block, with a split-plot arrangement of inoculum density as whole plot in four replicate blocks and nine fungicide treatments as subplot. Treatments again consisted of two fungicides applied at four growth stages, plus an untreated check (Table 1).

Urbana, IL. Field experiments similar to those described above were conducted at the University of Illinois Crop Sciences Research and Education Center near Urbana, during the 2012 (IL12) and 2013 (IL13) growing seasons. FHB susceptible, midseason SRWW cultivar Pioneer 25R47 was planted in $1.5 \times 6 \mathrm{~m}$ plots on 10 October 2011 and 11 October 2012. Plots were planted with a Great Plains no-till drill (3P606NT) at a seeding rate of approximately $3 \times 10^{6}$ seeds/ha. In both years, the experimental design was a randomized complete block, with 22 treatments randomly assigned to plots within each of four blocks. Treatments were in a factorial arrangement of two fungicides, five application timings, and two inoculum densities, plus an untreated check at each of the two inoculum densities (Table 1).

Fungicide application. The demethylation inhibitor (DMI) fungicide tebuconazole + prothioconazole (Prosaro 421 SC, abbreviated TEBU+PROT) was used at label-recommended rate (100 $\mathrm{g}$ of each a.i./ha) in all seven experiments, while the DMI metconazole (Caramba $90 \mathrm{SL}$, abbreviated METC) was used, also at labelrecommended rate (92 $\mathrm{g}$ a.i./ha), in five (WO13, SC11, SC13, IL12, and IL13) of the seven experiments. In all cases, a nonionic surfactant, Induce (Helena Chemical Co., Collierville, TN), was added to the fungicide mixture at a rate of $0.125 \% \mathrm{vol} / \mathrm{vol}$. Applications were made in the morning of the day on which the crop reached 50\% anthesis (Feekes GS 10.5.1) (i.e., when anthers were extruded in the central portion of the spikes on approximately $50 \%$ of the primary tillers) in all experiments, plus two to four additional application timings, at either 2, 3, 4, 5, or 6 days after $50 \%$ anthesis, depending on the experiment. We opted not to extend the treatment window beyond 6 days after $50 \%$ anthesis to minimize the chance of violating the legal 30-day preharvest intervals for METC and TEBU+PROT. Hereafter, applications made after 50\% Feekes 10.5.1 will be referred to as postanthesis applications. Anthesis applications will be abbreviated as A, and postanthesis applications as $\mathrm{A}+2, \mathrm{~A}+3, \mathrm{~A}+4, \mathrm{~A}+5$, and $\mathrm{A}+6$, respectively. Table 1 provides treatment details for each experiment.

For WO11, WO12, and WO13, fungicide applications were made using either a tractor mounted or backpack sprayer (R\&D Sprayers, Opelousas LA), with booms fitted with XR8001 nozzles (TeeJet Technologies, Dillsburg, PA), mounted at an angle $\left(45^{\circ}\right)$ forward and backward, and calibrated to apply at a rate of 187 liters/ha at $207 \mathrm{kPa}$. Fungicide treatments at SC11 and SC13 were applied using a $\mathrm{CO}_{2}$-pressurized backpack sprayer with a 3-m boom, fitted with 6 Teejet drift guard nozzles, DG 100-02, calibrated to apply at a rate of 187 liters/ha at $207 \mathrm{kPa}$. For IL12 and IL13, applications were also made using a $\mathrm{CO}_{2}$-pressurized backpack sprayer and handheld boom, equipped with 3 TwinJet XR8002 nozzles, at a rate of 187 liters/ha at a spray pressure of $276 \mathrm{kPa}$.

Inoculum preparation and inoculation. For experiments conducted in Ohio, inoculum was prepared using 10 aggressive isolates of F. graminearum (OHWAY1619, OHWAY627, OHWOO613, OHVAN4619, OHDEL3616, OHSHE6613, OHBUC6613, OHPAU2613, OHBUT611, and OHAUG621) of the 15-acetyl- 
deoxynivalenol (15-ADON) chemotype (D. Schmale, personal communication). Isolates were first grown on nutrient rich media (PDA, Komada), and then transferred to either mung bean agar (MBA) for macroconidia production, or carrot agar (CA) for ascospore production. Macroconidia were produced by incubating cultures for 7 to 10 days at room temperature under ultraviolet lights, with a 12-h photoperiod. Ascospore production was stimulated by using a sterilized rubber policeman to remove mycelium from CA plates (after about 4 days) in order to induce self-fertilization. Plates were then incubated at 22 to $25^{\circ} \mathrm{C}$ with a 10 -h photoperiod for another 10 to 14 days until perithecia were visible on the surface of the media. Sterile deionized water was then added to each MBA and CA plate, and macroconidia and ascospores were harvested by gently scraping the surface of the media with a rubber policeman. Spore concentrations were determined using a hemacytometer (Reichert-Bright Line, Hausser Scientific, Horsham, PA), and stock suspensions were stored at $-20^{\circ} \mathrm{C}$ until used for inoculation.

With the exception of SC11, where plots were naturally infected, all experiments were artificially spray-inoculated at early-to-midanthesis (in the evenings, approximately 12 to $36 \mathrm{~h}$ after the early anthesis fungicide treatments were applied) with inoculum concentrations ranging from $2 \times 10^{4}$ to $14 \times 10^{4}$ spores/ml (Table 1). For experiments conducted in Ohio, equal volumes and concentrations of ascospores and macroconidia were mixed prior to inoculation. Applications were made using a backpack sprayer (R\&D Sprayers) fitted with 3 flat fan XR8001 nozzles (TeeJet Technologies) equally spaced on a 3-m-long boom. By adjusting the pressure and application speed, the equipment was calibrated to administer ap- proximately $67 \mathrm{ml}$ of inoculum per $\mathrm{m}^{2}$ of plot. In Illinois (IL12 and IL13), $F$. graminearum macroconidia suspension inoculum was prepared using four $F$. graminearum isolates (Fg19, Fg28, Fg105, and Fg111) originally obtained from commercial Illinois wheat fields. Macroconidia were obtained by growing $F$. graminearum isolates in carboxymethyl-cellulose medium (36). Plot inoculations were similar to those described above for trials conducted in Ohio.

Data collection and analysis. Disease intensity was visually evaluated during the soft dough stage (Feekes GS 11.2) of crop development, approximately 3 weeks after anthesis. A total of 100 to 120 spikes were evaluated per plot. For WO11, WO12, and WO13, five clusters of 20 spikes were arbitrarily selected within each plot, for a total of 100 spikes, and evaluated for disease symptoms. For SC11 and SC13, six arbitrarily selected clusters of 20 spikes, for a total of 120 spikes, were scored for FHB symptoms, accounting for the larger plot sizes. In all cases, FHB index (field or plot severity) was visually estimated as the mean percentage of diseased spikelets per spike, and FHB incidence as the percentage of diseased spikes out of all spikes sampled. In Illinois, diseased-head severity and incidence were evaluated on 10 spikes per plot and then used to estimate index as the product of diseased head severity and incidence, as described previously $(28,34)$.

Depending on the location and year, plots were harvested between late June and mid-July, more than 30 days after the last $(\mathrm{A}+5$ or $\mathrm{A}+6)$ fungicide treatments were applied (Table 1$)$, using research plot combine harvesters. During harvest, grain samples were collected from each plot and later evaluated for Fusarium damaged kernels (FDK) by visually estimating percent diseased kernels (small, shriveled, and discolored). Additional grain samples

Table 1. Summary of inoculation and fungicide treatment application protocols for experiments conducted to evaluate the effects of postanthesis fungicide applications on Fusarium head blight of wheat

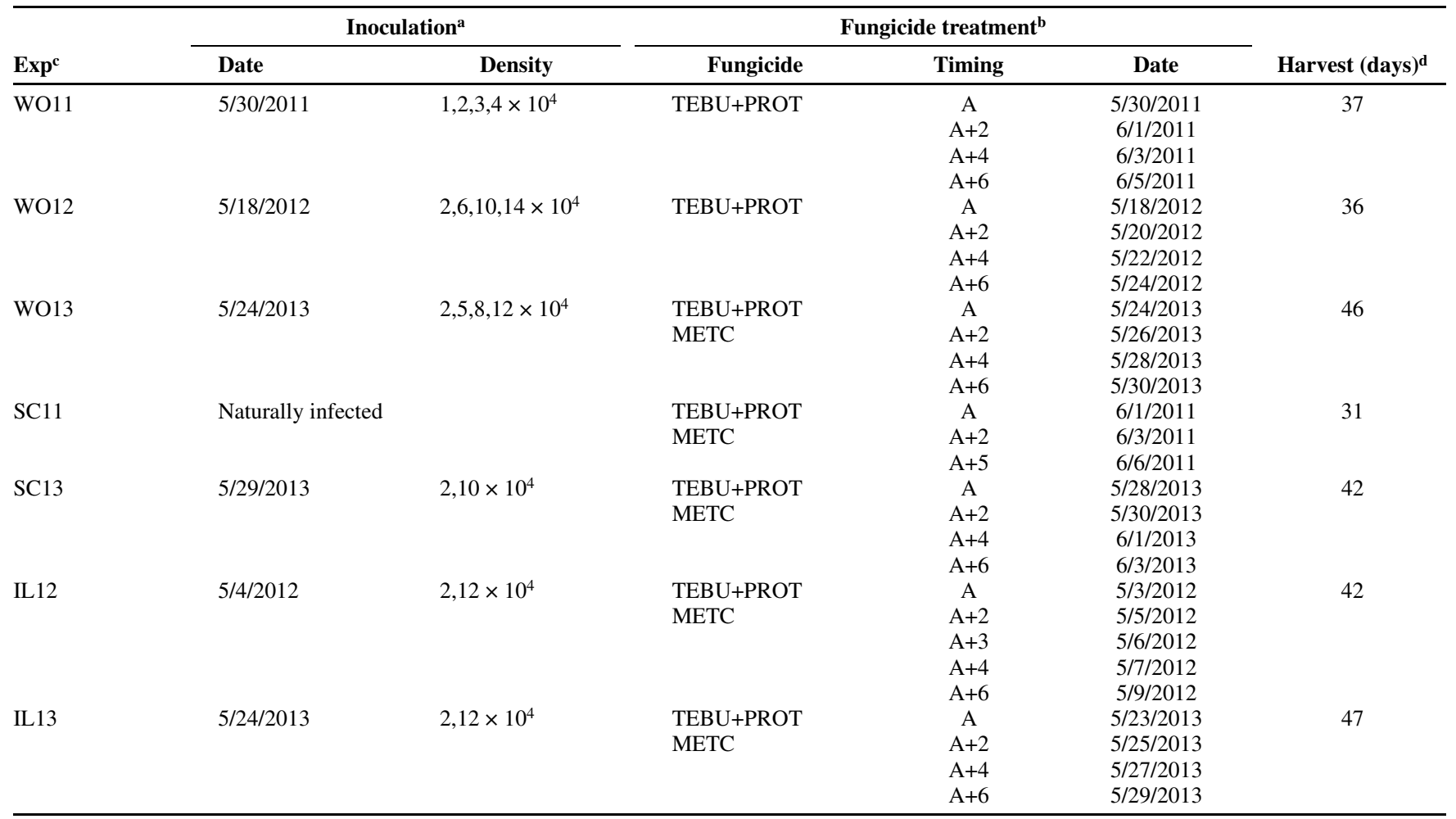

${ }^{a}$ Plots were either artificially inoculated or naturally infected. Artificial inoculation was done by spray-applying ascospore and/or macroconidia suspensions of Fusarium graminearum of densities ranging from 2-14 $\times 10^{4}$ spores $/ \mathrm{ml}$ using backpack sprayers. Applications were made at mid- or late-anthesis on the dates listed.

${ }^{\mathrm{b}}$ Fungicide treatments consisted of the application of prothioconazole + tebuconazole (TEBU+PROT) at $100 \mathrm{~g}$ of each a.i. per ha or metconazole (METC) at $92 \mathrm{~g}$ a.i. per ha at anthesis (A, Feekes growth stage 10.5.1), or at 2, 3, 4, 5, or 6 days after anthesis ( $\mathrm{A}+2, \mathrm{~A}+3, \mathrm{~A}+4, \mathrm{~A}+5$, and $\mathrm{A}+6$, respectively), on the dates indicated. Untreated checks were included in all trials

${ }^{\mathrm{c}}$ Field experiments conducted between 2011 and 2013 at the Ohio Agricultural Research and Development Center (OARDC) Snyder Farm near Wooster, OH (WO11, WO12, and WO13); OARDC Western Agricultural Research Station near South Charleston, OH (SC11 andSC13); and at the the University of Illinois Crop Sciences Research and Educationn Center near Urbana, IL (IL12 and IL13).

${ }^{\mathrm{d}}$ Harvest $($ days $)=$ number of days plots were harvested after the last $(\mathrm{A}+5$ or $\mathrm{A}+6)$ fungicide application . 
were ground using a coffee grinder (Braun Aromatic KSM 2 B, Gillette Commercial, Boston, MA) or a laboratory mill (Laboratory Mill 3033, Perten Instruments, Springfield, IL), and sent to the U.S. Wheat and Barley Scab Initiative mycotoxin testing laboratory in the Department of Plant Pathology, University of Minnesota, St. Paul, for DON quantification by gas chromatographymass spectrometry (GC-MS).

All data were analyzed using PROC GLIMMIX in SAS (SAS, Cary, NC) (21) in order to evaluate the effects of fungicide application timing and, where applicable, cultivar, fungicide active ingredient, inoculum density, and their interactions on FHB, FDK, and DON. Prior to the analyses, FHB incidence, index, and FDK data were arcsine-square-root-transformed and DON was log-transformed to stabilize variances. Each experiment was analyzed separately, with application timing, cultivar, fungicide, and inoculum density treated as fixed effects, and block and all interactions involving block (in the case of split-plot experiments) treated as random effects in the analyses. For all statistically significant effects, contrast and lsmestimate statements in GLIMMIX were used to compare postanthesis applications with the untreated check and the anthesis application.

Percent control of FHB index and DON. Percent control, defined as:

$$
C=\left\lfloor\left(\bar{X}_{\text {check }}-\bar{X}_{\text {Timing }}\right) / \bar{X}_{\text {check }}\right\rfloor \cdot 100
$$

where $\bar{X}$. represents mean for an application timing or control, is a useful matrix for growers to determine the efficacy of a particular fungicide treatment in terms of disease control. Data from the seven experiments were therefore used to estimate mean percent control $(\bar{C})$ of index and DON for all application timings relative to the untreated check and for postanthesis applications relative to the anthesis application (where $\bar{X}_{\text {check }}$ is replaced by $\bar{X}_{A}$ in the above expression), based on multivariate random-effects metaanalyses $(30,39)$. For experiments with both resistant and susceptible cultivars (WO2011 and WO2012), the untreated susceptible check was used as the reference for estimating percent control. Each whole-plot in split-plot experiments was treated as a separate experiment, and mean IND and DON, averaged across inoculum densities (where applicable), as well as their standard error were used for the meta-analyses. Sampling variances of the means were estimated from linear mixed model analyses (21) of the individual trial data, and the meta-analytical models were fitted with $\log$ response ratio $(L)$ as the effect size, following the approach described by Willyerd et al (39). Mean percent control for IND and DON across the experiments and their 95\% confidence intervals were estimated from mean $L(\bar{L})$ values and their confidence intervals as:

$$
\bar{C}=[1-\exp (\bar{L})] \times 100
$$

\section{Results}

FHB and toxin levels. Mean disease and toxin levels varied among years and locations. During the Wooster, OH, 2011 (WO11) wheat field season, averaged across inoculum density and replicates, mean disease index (IND, mean proportion of diseased spikelets per spike) ranged from 1.6 to $10.4 \%$ (Fig. 1A), and mean DON levels from 0.13 to $1.56 \mathrm{ppm}$ (Fig. 2A). In 2012 (WO12), an unusually dry season, both IND and DON levels were much lower, with mean IND ranging from 0.4 to $2.4 \%$, and mean DON from 0.01 to $0.57 \mathrm{ppm}$ (Fig. 1B). In 2013 (WO13), the corresponding mean ranges were 0.6 to $4.2 \%$ for IND and 1.11 to $2.21 \mathrm{ppm}$ for DON. It is interesting to note that the upper limit for mean DON for the 2013 experiment was in anthesis treated plots, not the untreated check (Figs. 1C and 2B).

For the 2011 experiment conducted at South Charleston, OH (SC11), a location and year with natural rainfall during anthesis and natural infection, averaged across fungicide active ingredients and inoculum densities, mean IND levels ranged from 2 to $12 \%$ (Fig. 1D), and mean DON from 2.6 to 7.7 ppm (Fig. 2C). In 2013, mean IND in an inoculated trial at that same location (SC13) ranged from 2.3 to $9.4 \%$, and mean DON from 0.91 to $2.5 \mathrm{ppm}$
(Figs. 1E and 2D). The corresponding mean disease and toxin ranges (averaged across inoculum densities and active ingredients) for experiments conducted in Illinois in 2012 (IL12) and 2013 (IL13) were 0.3 to $30.8 \%$ (Fig. 1F) and 0.13 to $0.38 \mathrm{ppm}$ for mean IND and DON in 2012, and 17.3 to $37.8 \%$ and 5.8 to $11.8 \mathrm{ppm}$ for mean IND and DON in 2013 (Figs. $1 \mathrm{G}$ and 2E).

In all seven experiments, with the exception of Wooster 2013, very similar trends were observed, with the upper disease and toxin limits being derived from mean levels in the untreated checks (Figs. 1 and 2). In general, all plots treated with PROT+TEBU, both at and after anthesis, had considerably lower mean IND and DON than the untreated check (Figs. 1 and 2). For experiments with different cultivars (WO11 and WO12) and different fungicides (WO13, SC11, SC13, IL12, and IL13) (Prosaro and Caramba; PROT+TEBU and METC, respectively), similar trends were observed, with treated plots having lower mean levels of IND and DON than the check. However, the susceptible cultivar (Figs. $1 \mathrm{~A}$ and $\mathrm{B}$, and $2 \mathrm{~A}$ ) and plots treated with PROT+TEBU (Figs. 1C, $\mathrm{D}, \mathrm{E}, \mathrm{F}$, and $\mathrm{G}$, and $2 \mathrm{~B}, \mathrm{C}, \mathrm{D}$, and $\mathrm{E}$ ) tended to have higher mean disease and toxin levels than the moderately resistant cultivar and plots treated with METC, respectively.

Fungicide, cultivar, and inoculation effects on disease and toxin levels. Results from linear mixed model analyses of the effects of one or more of the following fixed-effect treatment factors or combination of factors-cultivar, fungicide active ingredient, application timing, and inoculum density-on arcsine-square-roottransformed FHB index (arcIND), incidence ( $\operatorname{arcINC}$ ), and FDK (arcFDK), and $\log$-transformed DON $(\log \mathrm{DON})$ are summarized in Table 2. For trials with three fixed-effect factors (WO11, WO12, and WO13), the three-way interactions were not statistically significant for any of the measured responses (Table 2). Similarly, for trials with at least two of the four tested treatment factors (WO11, WO12, WO13, and SC13), in general, none of the two-way interactions were statistically significant for any of the measured responses. For SC11, in which treatments consisted of a factorial arrangement of fungicide active ingredient and application timing, and IL12 and IL13, in which treatments consisted of a factorial arrangement of fungicide active ingredient, timing, and inoculum density, results from linear contrasts of least squares means showed that the effect of application timing was not influenced by active ingredient, inoculum density, or active ingredient*inoculum density interaction (data not shown).

For all experiments, pairwise contrasts of LS means for each of the reference treatments (untreated check and anthesis application) with each of the postanthesis fungicide applications were performed based on the results of the linear mixed model analyses. Contrast results were used to determine fungicide effects on $\operatorname{arcIND}$, arcINC, arcFDK, and $\log D O N$. Since the results for arcINC and arcFDK were very similar to those observed for arcIND, only the latter response and $\log \mathrm{DON}$ are shown in Table 3 and discussed hereafter. In general, similar trends were observed across all experiments, for all years and locations. In all cases, mean arcIND was significantly lower for the anthesis and postanthesis fungicide applications compared to the untreated check (Table $3, P<0.01)$. With two exceptions, there was no significant difference between the means for the anthesis applications (A) and means for any of the postanthesis applications $(\mathrm{A}+2, \mathrm{~A}+4, \mathrm{~A}+5$, or $A+6)$. The only exceptions were for SC11, the naturally infected experiment, in which it rained during anthesis $(33 \mathrm{~mm}$ on the day the fungicide was applied and $39 \mathrm{~mm}$ on the day after), and WO13, the study in which it was very cold during and shortly after anthesis (mean, max, and min temperatures $8.5,22.8$, and $-1.6^{\circ} \mathrm{C}$, respectively, for $48 \mathrm{~h}$ beginning at the time of fungicide application). In the former experiment, averaged across PROT+TEBU and METC, the application made 2 days after anthesis had significantly lower mean IND than the anthesis application. A similar, but marginal effect $(P<0.10)$ was observed for the application made 5 days after anthesis. For WO13, averaged across PROT+TEBU and METC, all postanthesis applications $(\mathrm{A}+2, \mathrm{~A}+4$, and $\mathrm{A}+6)$ had significantly lower mean arcIND that the anthesis application. 
Very similar trends were observed for DON. For trials with $>1$ ppm DON in the untreated check, all fungicide treatments generally had significantly lower $\log$ DON than the untreated check $(P<$ 0.001 ), and differences between anthesis and postanthesis applications were generally not statistically significant (Table 3; WO11 and SC13). SC11 and WO13 were again the exceptions, showing responses very similar to those described above for arcIND. However, with toxin, the A+5 application timing for the SC11 trial had significantly higher $\log \mathrm{DON}$ than the anthesis application timing (Table 3). For WO13, there were elevated DON levels in the
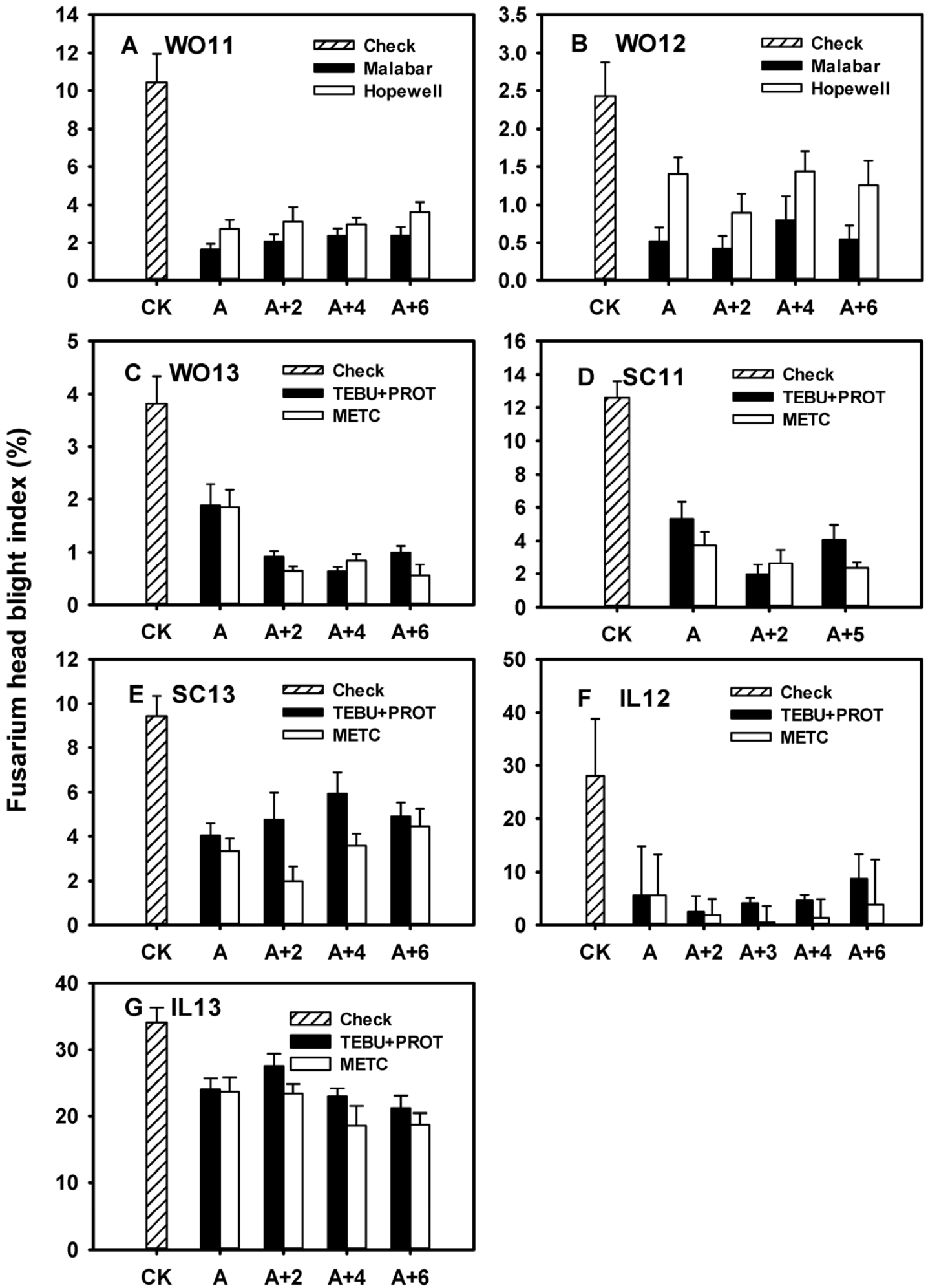

Fig. 1. Mean Fusarium head blight index (mean proportion of diseased spikelets per spike) for different fungicide treatments applied to soft red winter wheat (SRWW) in field experiments conducted at the Ohio Agricultural Research and Development Center (OARDC) Snyder Farm near Wooster, OH in 2011 (A), 2012 (B), and 2013 (C); at the OARDC Western Agricultural Research Station near South Charleston, OH in 2011 (D) and 2013 (E); and at the University of Illinois Crop Sciences Research and Education Center near Urbana, IL in 2012 (F) and 2013 (G). Treatments were Check = Untreated control (CK), A = tebuconazole + prothioconazole fungicide (TEBU+PROT, in all trials) or metconazole (METC, in the trials indicated) application made at $50 \%$ anthesis and $A+2, A+3, A+4, A+5$, and $A+6=$ applications made at $2,3,4,5$, and 6 days after anthesis, respectively. Malabar and Hopewell $=$ moderately resistant and susceptible midseason SRWW cultivars, respectively. Bars represent means across 4 to 24 experimental units (i.e., across the levels of the other treatment factors in the study) and their corresponding standard error. 
anthesis application compared to the untreated check as well as all of the postanthesis applications, with the difference being statistically significant for all postanthesis applications $(P<0.001$; Table 3$)$.

Percent control of FHB index and DON. Results from the meta-analyses are summarized in Table 4. Based on the standard normal test ( $Z$ statistic in the table), log response ratios between the check $(\mathrm{CK})$ and the fungicide treatments, regardless of timing, were significantly different from zero for both FHB index (IND) and DON $(P<0.001)$. The application made 2 days after anthesis $(\mathrm{A}+2)$ had the highest negative $\bar{L}$ values, -1.18 for IND and -0.77 for DON, and correspondingly, the highest $\bar{C}$ values relative to the check, 69 and 54\%, for IND and DON, respectively. $\bar{C}$ for the other application timings were 56 and $50 \%$ for the anthesis application, 62 and $52 \%$ for the application made 4 days after anthesis $(\mathrm{A}+4)$, and 62 and $48 \%$ for the 6-day postanthesis application (A+6) (Table 4), for IND and DON, respectively.

For IND, $\bar{L}$ values between anthesis and postanthesis treatments were significantly different from zero for A+2 and A+6 $(P<$
$0.05)$, and marginally significant for $\mathrm{A}+4(P=0.09)$. Relative to the anthesis application, $\mathrm{A}+2, \mathrm{~A}+4$, and $\mathrm{A}+6$ further reduced $\mathrm{FHB}$ index by an average of 30,13 , and $14 \%$, respectively, but the lower confidence limit was below or near zero for the A+4 and A+6 treatments (Table 4). Postanthesis applications were not significantly more effective than the anthesis application against DON across the experiments (i.e., $\bar{L}$ was not significantly different from zero). Although the $\mathrm{A}+2$ and $\mathrm{A}+4$ applications reduced DON an average 8 and $6 \%$, respectively, the lower confidence limits were below zero for all postapplications.

\section{Discussion}

Our findings summarize multiple years of field experiments conducted under a range of SRWW growing conditions in Ohio and Illinois to assess the benefits of applying a fungicide up to 6 days postanthesis for FHB and DON management. This was the first comprehensive U.S.-based study to formally assess the efficacy of tebuconazole + prothioconazole (TEBU+PROT; Prosaro) and
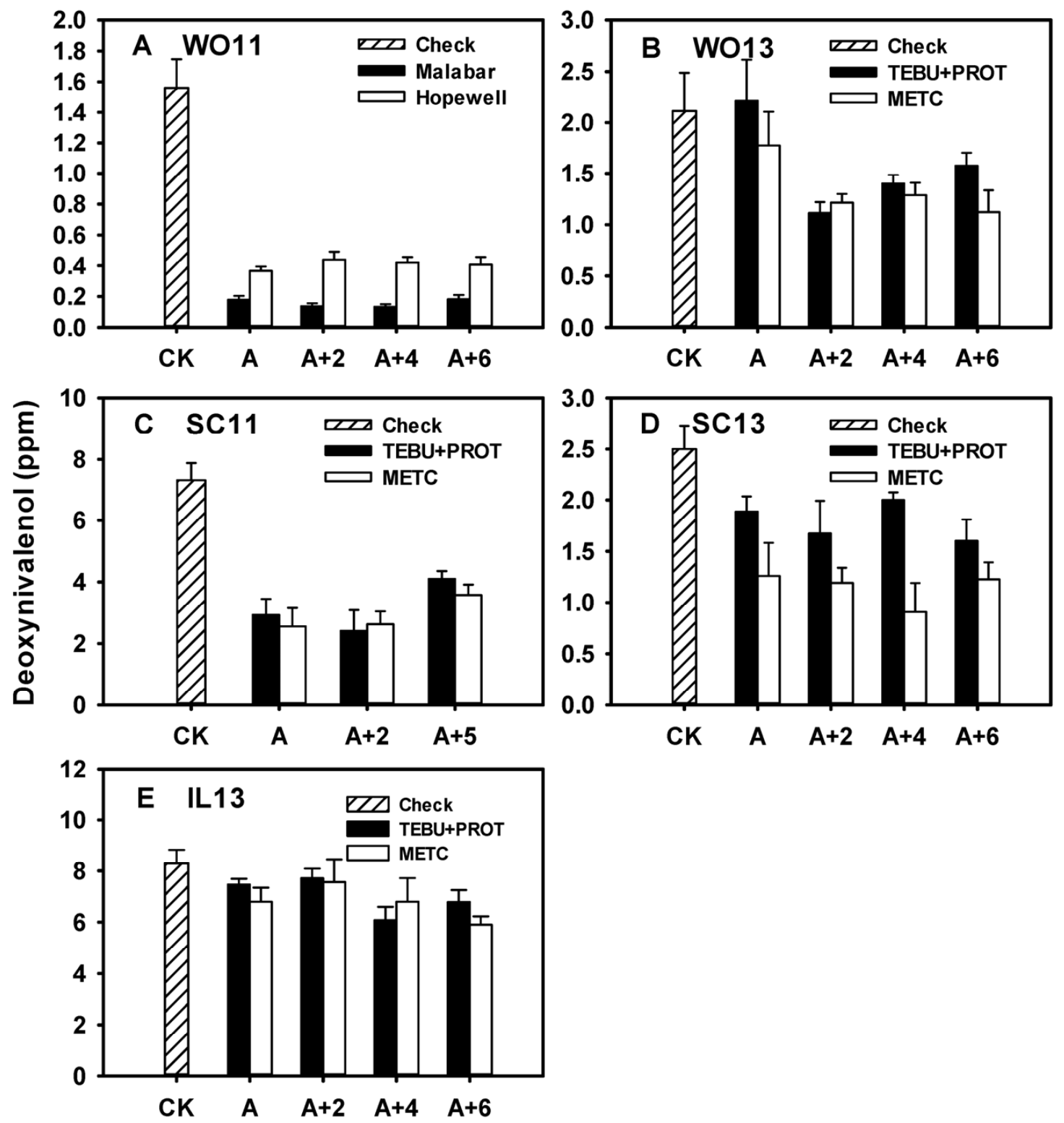

Fig. 2. Mean deoxynivalenol content of harvested grain for different fungicide treatments applied to soft red winter wheat (SRWW) in field experiments conducted at the Ohio Agricultural Research and Development Center (OARDC) Snyder Farm near Wooster, OH in 2011 (A) and 2013 (B), at OARDC Western Agricultural Research Station near South Charleston, $\mathrm{OH}$ in 2011 (C) and 2013 (D), and at University of Illinois Crop Sciences Research and Education Center near Urbana, IL in 2013 (E). Treatments were Check = untreated check (CK), $A=$ tebuconazole + prothioconazole fungicide (TEBU+PROT, in all trials) or metconazole (METC, in the trials indicated) application made at $50 \%$ anthesis and $A+2, A+3, A+4, A+5$, and $A+6=$ applications made at 2, 3, 4, 5, and 6 days after anthesis, respectively. Malabar and Hopewell $=$ moderately resistant and susceptible midseason SRWW cultivars, respectively. Bars represent means across 4 to 24 experimental units (i.e., across the levels of the other treatment factors in the study) and their corresponding standard error. 
metconazole (METC; Caramba), the two most effective fungicides against FHB and DON (30), when applied within a narrow window (up to 1 week) postanthesis. Despite the difference in baseline levels of FHB and DON among location-years, we consistently found significantly lower levels of IND, DON, and FDK in anthesis as well as all postanthesis fungicide applications compared to the untreated check in all seven field trials. In general, there was no degradation of fungicide efficacy by extending the application up to 6 days after $50 \%$ anthesis. In some instances, postanthesis fungicide applications provided better control of IND or DON than the anthesis application. The effects of cultivar (moderately resistant and susceptible) varied among experiments, but did not affect postanthesis application effects on IND or DON based on the nonsignificant interactions. Across years and locations, there was no significant interaction of fungicide active ingredient and application timing, or of inoculum densities and application timings, further emphasizing the consistency of the postanthesis fungicide application effect. Overall, there was an average of 56 to $69 \%$ control of FHB index and a 48 to $54 \%$ control of DON when either tebuconazole + prothioconazole or metconazole was applied at or up to 6 days after anthesis. These means are within the range of values found in a larger meta-analysis of the effects of these same fungicides applied at anthesis (30).

Several factors may have been responsible for the observed success of postanthesis fungicide applications on FHB and DON, including successful control of pathogen colonization after infection had occurred, successful control of postanthesis infections, asynchronous development of tillers in wheat plots (so that susceptible spikes occurred after anthesis of primary tillers), and the interaction of these factors with weather conditions. Several studies have demonstrated that "late" infections of wheat spikes do occur $(10,18,20,40)$, which could affect both FHB symptom development and DON production. However, several of these studies also showed that the highest level of FHB was observed when infections occurred at anthesis compared to after anthesis. So, anthesis would seem to be the optimum time for applying a preventative fungicide to control FHB as well as for spray-inoculating plots as was done in this investigation. However, accurately determining when anthesis actually occurs in a population of wheat spikes in the field is a challenge. The $50 \%$ anthesis fungicide recommendation often used for FHB control and for spray inoculation commonly refers to the growth stage of primary tillers. Therefore, anthesis for primary tillers may in fact be preanthesis for secondary tillers. Similarly, postanthesis for primary tillers may actually be anthesis for secondary tillers. Synchrony of crop development and tillering are influenced by several factors, such as cultivar characteristics, weather conditions, and crop husbandry (row spacing, planting density, and fertility program), which as a consequence may affect fungicide performance and the success of artificial spray inoculations.

Table 2. Summary statistics from linear mixed model analyses of data from field experiments conducted in multiple location-years to evaluate the effects of postanthesis fungicide application timings (TIMING) on Fusarium head blight index (IND), incidence (INC), Fusarium damaged kernel (FDK) and deoxynivalenol (DON) in soft red winter wheat as influenced by wheat cultivar (CV), fungicide active ingredient (FUN), and inoculum density (INOC)

\begin{tabular}{|c|c|c|c|c|c|c|c|c|c|}
\hline \multirow[b]{2}{*}{ Experiment $^{b}$} & \multirow[b]{2}{*}{ Factors $^{\mathrm{c}}$} & \multicolumn{2}{|c|}{ IND $^{\mathbf{a}}$} & \multicolumn{2}{|c|}{ INC $^{\mathbf{a}}$} & \multicolumn{2}{|c|}{ FDK $^{\mathbf{a}}$} & \multicolumn{2}{|c|}{ DON $^{a}$} \\
\hline & & $F$ value $^{\text {d }}$ & $P^{d}$ & $F$ value & $P$ & $F$ value & $P$ & $F$ value & $P$ \\
\hline \multirow[t]{7}{*}{ WO11 } & $\mathrm{CV}$ & 10.04 & 0.087 & 3.99 & 0.184 & 47.56 & 0.020 & 39.40 & 0.024 \\
\hline & TIMING & 5.47 & 0.006 & 3.74 & 0.025 & 28.06 & $<0.001$ & 31.77 & $<0.001$ \\
\hline & TIMING*CV & 0.70 & 0.601 & 0.09 & 0.985 & 2.04 & 0.137 & 1.23 & 0.336 \\
\hline & INOC & 0.23 & 0.875 & 0.21 & 0.890 & 1.42 & 0.246 & 0.04 & 0.987 \\
\hline & CV*INOC & 0.71 & 0.550 & 1.32 & 0.277 & 1.04 & 0.380 & 0.78 & 0.510 \\
\hline & TIMING*INOC & 0.46 & 0.931 & 0.60 & 0.831 & 1.40 & 0.190 & 0.73 & 0.716 \\
\hline & TIMING*CV*INOC & 1.05 & 0.421 & 1.23 & 0.285 & 1.02 & 0.443 & 1.19 & 0.314 \\
\hline \multirow{7}{*}{ WO12 } & $\mathrm{CV}$ & 55.58 & $<0.001$ & 68.92 & $<0.001$ & $\ldots$ & $\ldots{ }^{\mathrm{e}}$ & $\ldots$ & $\ldots$ \\
\hline & TIMING & 6.33 & 0.001 & 5.44 & 0.002 & $\ldots$ & $\ldots$ & $\ldots$ & $\ldots$ \\
\hline & TIMING*CV & 0.83 & 0.512 & 0.73 & 0.577 & $\ldots$ & $\ldots$ & $\ldots$ & $\ldots$ \\
\hline & INOC & 0.62 & 0.627 & 1.06 & 0.438 & $\ldots$ & $\ldots$ & $\ldots$ & $\ldots$ \\
\hline & CV*INOC & 3.28 & 0.031 & 3.09 & 0.039 & $\ldots$ & $\ldots$ & $\ldots$ & $\ldots$ \\
\hline & TIMING*INOC & 1.65 & 0.129 & 1.62 & 0.141 & $\ldots$ & $\ldots$ & $\ldots$ & $\ldots$ \\
\hline & TIMING*CV*INOC & 1.74 & 0.096 & 1.61 & 0.131 & $\ldots$ & $\ldots$ & $\ldots$ & $\ldots$ \\
\hline \multirow{7}{*}{ WO13 } & FUN & 3.75 & 0.057 & 3.51 & 0.098 & 0.38 & 0.558 & 1.94 & 0.168 \\
\hline & TIMING & 53.07 & $<0.001$ & 45.60 & $<0.001$ & 27.34 & $<0.001$ & 11.90 & $<0.001$ \\
\hline & TIMING*FUN & 1.73 & 0.154 & 2.02 & 0.103 & 0.27 & 0.895 & 1.45 & 0.228 \\
\hline & INOC & 1.82 & 0.243 & 1.86 & 0.238 & 0.23 & 0.875 & 2.50 & 0.155 \\
\hline & FUN*INOC & 0.58 & 0.627 & 2.04 & 0.187 & 1.30 & 0.346 & 0.78 & 0.509 \\
\hline & TIMING*INOC & 1.05 & 0.417 & 1.35 & 0.214 & 0.24 & 0.995 & 0.90 & 0.554 \\
\hline & TIMING*FUN*INOC & 0.96 & 0.496 & 0.98 & 0.478 & 1.41 & 0.184 & 1.70 & 0.086 \\
\hline SC11 & TRT & 24.63 & $<0.001$ & 15.01 & $<0.001$ & 8.95 & $<0.001$ & 11.06 & $<0.001$ \\
\hline \multirow[t]{3}{*}{$\mathrm{SC} 13$} & TRT & 5.93 & $<0.001$ & 3.76 & 0.001 & $\ldots$ & $\ldots$ & 5.06 & $<0.001$ \\
\hline & INOC & 4.57 & 0.038 & 0.26 & 0.656 & $\ldots$ & $\ldots$ & 0.66 & 0.421 \\
\hline & TRT*INOC & 0.86 & 0.567 & 0.91 & 0.529 & $\ldots$ & $\ldots$ & 1.76 & 0.104 \\
\hline IL12 & TRT & 4.24 & $<0.001$ & 1.92 & 0.025 & 0.78 & 0.729 & 1.67 & 0.061 \\
\hline IL13 & TRT & 3.06 & 0.001 & 1.52 & 0.126 & 1.40 & 0.176 & 1.41 & 0.174 \\
\hline
\end{tabular}

${ }^{a}$ IND = Fusarium head blight index (mean proportion of diseased spikelets per spike); INC = Fusarium head blight incidence (mean proportion of diseased spikes); FDK = Fusarium damaged kernels (percentage of visually shriveled, small, and discolored kernels); DON = deoxynivalenol content of harvested grain (ppm).

${ }^{\mathrm{b}}$ Field experiments conducted between 2011 and 2013 at the Ohio Agricultural Research and Development Center (OARDC) Snyder Farm near Wooster, $\mathrm{OH}$, under artificial inoculation (WO11, WO12, and WO13); at the OARDC Western Agricultural Research Station near South Charleston, OH, under natural infection (SC11) and artificial inoculation (SC13); and at the University of Illinois Crop Sciences Research and Education Center near Urbana, IL under artificial inoculation (IL12 and IL13).

${ }^{c}$ TIMING = fungicide application timing consisting of an untreated check, an application made at anthesis (Feekes growth stage 10.5.1), plus one or more postanthesis applications $(2,3,4,5$, or 6 days after anthesis); $\mathrm{CV}=$ wheat cultivars with different levels of resistance to FHB (Hopewell, susceptible, and Malabar, moderately susceptible); INOC = concentration of Fusarium graminearum inoculum used to spray inoculate plots; and FUN = DMI fungicides prothioconazole + tebuconazole (100 $\mathrm{g}$ of each a.i./ha) and metconazole (92 $\mathrm{g}$ a.i./ha). For the IL12 and IL13 experiments, treatments (TRT) consisted of various combinations of TIMING $\times$ INOC $\times$ FUN. For SC11 and SC13, TRT consisted of various combinations of TIMING $\times$ FUN

${ }^{\mathrm{d}} F=F$ statistic and $P=$ probability (level of significance) based on mixed model analyses of arcsine-transformed IND, INC, and FDK and log-transformed DON data.

${ }^{\mathrm{e}}$ Missing because data were not collected, or in the case on DON, levels were too low $(<0.06 \mathrm{ppm})$ for evaluation of treatment effects. 
Plots in six of the seven experiments in this investigation were spray inoculated with fairly high spore densities at midanthesis, approximately 12 to $36 \mathrm{~h}$ after the anthesis applications were made, but 1 to 5 days before the postanthesis applications. Therefore, it seems reasonable to assume that the resulting disease and toxin levels were largely due to the artificial inoculations rather than natural inoculum, and to infections at anthesis (at least for primary tillers) rather than late infections. Furthermore, given the inoculation and treatment protocols used in these studies, one may further assume that post-anthesis-treated plots not subjected to the preventative or protective action of the fungicides were equally likely to be infected during the critical anthesis growth stage as the untreated check. The observed efficacy (percent control) of postanthesis applications against index and DON relative to the untreated check could therefore be attributed, at least in part, to reduction of fungal spread within the spike and visual symptom development

Table 3. Summary statistics from linear mixed model analyses of postanthesis fungicide application effects on Fusarium head blight index (IND) and deoxynivalenol (DON), showing $F$ statistics and $P$ values for comparisons between each application timing and the check and between anthesis and postanthesis applications

\begin{tabular}{|c|c|c|c|c|c|}
\hline \multirow[b]{2}{*}{ Experiment $^{\text {b }}$} & \multirow[b]{2}{*}{ Contrast $^{\mathrm{c}}$} & \multicolumn{2}{|c|}{ IND $^{\mathbf{a}}$} & \multicolumn{2}{|c|}{ DON $^{a}$} \\
\hline & & Diff $^{d}$ & $F$ value $(P)^{\mathrm{e}}$ & Diff & $F$ value $(P)$ \\
\hline \multirow[t]{7}{*}{ WO11 } & Check vs. A & 5.48 & $16.70(<0.001)$ & 0.79 & $76.80(<0.001)$ \\
\hline & Check vs. $\mathrm{A}+2$ & 5.07 & $14.06(0.002)$ & 0.77 & $84.30(<0.001)$ \\
\hline & Check vs. A+4 & 4.99 & $11.94(0.003)$ & 0.79 & $84.58(<0.001)$ \\
\hline & Check vs. A+6 & 4.66 & $10.21(0.006)$ & 0.77 & $70.24(<0.001)$ \\
\hline & A vs. A+2 & -0.41 & $0.11(0.741)$ & -0.02 & $0.17(0.681)$ \\
\hline & A vs. A+4 & -0.49 & $0.40(0.537)$ & 0.00 & $0.19(0.671)$ \\
\hline & A vs. A+6 & -0.82 & $0.79(0.386)$ & -0.02 & $0.15(0.707)$ \\
\hline \multirow[t]{7}{*}{ WO12 } & Check vs. A & 0.69 & 8.33 (0.007) & $\ldots^{\mathrm{f}}$ & $\ldots$ \\
\hline & Check vs. $A+2$ & 1.00 & $23.79(<0.001)$ & $\ldots$ & $\ldots$ \\
\hline & Check vs. A+4 & 0.54 & $4.74(0.037)$ & $\ldots$ & $\ldots$ \\
\hline & Check vs. A+6 & 0.75 & $10.61(0.003)$ & $\ldots$ & $\ldots$ \\
\hline & A vs. A+2 & 0.30 & $3.96(0.055)$ & $\ldots$ & $\ldots$ \\
\hline & A vs. $A+4$ & -0.17 & $0.55(0.463)$ & $\ldots$ & $\ldots$ \\
\hline & A vs. A+6 & 0.06 & $0.14(0.713)$ & $\ldots$ & $\ldots$ \\
\hline \multirow[t]{7}{*}{ WO13 } & Check vs. A & 1.94 & $44.41(<0.001)$ & 0.12 & $0.33(0.325)$ \\
\hline & Check vs. $\mathrm{A}+2$ & 3.03 & $130.64(<0.001)$ & 0.95 & $32.53(<0.001)$ \\
\hline & Check vs. A+4 & 3.07 & $137.31(<0.001)$ & 0.77 & $13.27(<0.001)$ \\
\hline & Check vs. A+6 & 3.04 & $142.07(<0.001)$ & 0.76 & $16.93(<0.001)$ \\
\hline & A vs. A+2 & 1.09 & $22.71(<0.001)$ & 0.83 & $26.35(<0.001)$ \\
\hline & A vs. A+4 & 1.13 & $25.54(<0.001)$ & 0.65 & $9.55(0.003)$ \\
\hline & A vs. A+6 & 1.09 & $27.62(<0.001)$ & 0.65 & $12.56(<0.001)$ \\
\hline \multirow[t]{5}{*}{ SC11 } & Check vs. A & 8.10 & $59.36(<0.001)$ & 4.58 & $43.3(<0.001)$ \\
\hline & Check vs. A+2 & 10.31 & $119.88(<0.001)$ & 4.80 & $52.42(<0.001)$ \\
\hline & Check vs. A+5 & 9.41 & $90.0(<0.001)$ & 3.48 & $16.38(<0.001)$ \\
\hline & A vs. $A+2$ & 2.21 & $10.52(0.004)$ & 0.22 & $0.43(0.517)$ \\
\hline & A vs. A+5 & 1.32 & $3.18(0.088)$ & -1.10 & $6.41(0.019)$ \\
\hline \multirow[t]{7}{*}{$\mathrm{SC} 13$} & Check vs. A & 5.69 & $28.72(<0.001)$ & 0.93 & $10.45(<0.001)$ \\
\hline & Check vs. $\mathrm{A}+2$ & 5.88 & $36.24(<0.001)$ & 1.05 & $16.20(<0.001)$ \\
\hline & Check vs. A+4 & 4.66 & $17.32(<0.001)$ & 1.05 & $14.78(<0.001)$ \\
\hline & Check vs. A+6 & 4.72 & $16.65(<0.001)$ & 1.11 & $14.98(<0.001)$ \\
\hline & A vs. A+2 & 0.32 & $0.75(0.389)$ & 0.14 & $0.98(0.329)$ \\
\hline & A vs. $A+4$ & -1.06 & $1.56(0.218)$ & 0.12 & $0.68(0.414)$ \\
\hline & A vs. A+6 & -0.98 & $1.39(0.243)$ & 0.16 & $0.92(0.344)$ \\
\hline \multirow[t]{9}{*}{ IL12 } & Check vs. A & 22.50 & $41.78(<0.001)$ & $\mathrm{ns}^{\mathrm{g}}$ & ns \\
\hline & Check vs. $\mathrm{A}+2$ & 25.91 & $57.98(<0.001)$ & ns & $\mathrm{ns}$ \\
\hline & Check vs. A+3 & 25.78 & $58.71(<0.001)$ & ns & ns \\
\hline & Check vs. A+4 & 25.13 & $48.94(<0.001)$ & ns & ns \\
\hline & Check vs. A+6 & 21.78 & $34.54(<0.001)$ & $\mathrm{ns}$ & ns \\
\hline & A vs. A+2 & 3.41 & $1.99(0.163)$ & ns & ns \\
\hline & A vs. $A+3$ & 3.28 & $2.15(0.147)$ & $\mathrm{ns}$ & $\mathrm{ns}$ \\
\hline & A vs. A+4 & 2.63 & $0.42(0.518)$ & $\mathrm{ns}$ & $\mathrm{ns}$ \\
\hline & A vs. A+6 & -0.72 & $0.52(0.475)$ & $\mathrm{ns}$ & ns \\
\hline \multirow[t]{7}{*}{ IL13 } & Check vs. A & 10.30 & $15.2(<0.001)$ & $\mathrm{ns}$ & $\mathrm{ns}$ \\
\hline & Check vs. A+2 & 8.69 & $10.90(0.002)$ & $\mathrm{ns}$ & $\mathrm{ns}$ \\
\hline & Check vs. A+4 & 13.38 & $28.32(<0.001)$ & $\mathrm{ns}$ & ns \\
\hline & Check vs. A+6 & 14.19 & $31.43(<0.001)$ & $\mathrm{ns}$ & $\mathrm{ns}$ \\
\hline & A vs. A+2 & -1.62 & $0.61(0.437)$ & $\mathrm{ns}$ & ns \\
\hline & A vs. A+4 & 3.07 & $2.69(0.107)$ & ns & ns \\
\hline & A vs. $A+6$ & 3.88 & $3.93(0.053)$ & $\mathrm{ns}$ & ns \\
\hline
\end{tabular}

${ }^{\mathrm{a}} \mathrm{IND}=$ Fusarium head blight index (mean proportion of diseased spikelets per spike) and DON = deoxynivalenol content of harvested grain (ppm).

${ }^{b}$ Field experiments conducted between 2011 and 2013 at the Ohio Agricultural Research and Development Center (OARDC) Snyder Farm near Wooster, $\mathrm{OH}$, under artificial inoculation (WO11, WO12, and WO13); at the OARDC Western Agricultural Research Station near South Charleston, OH, under natural infection (SC11) and artificial inoculation (SC13); and at the University of Illinois Crop Sciences Research and Educaiton Center near Urbana, IL under artificial inoculation (IL12 and IL13).

${ }^{\mathrm{c}}$ Check $=$ untreated check, $\mathrm{A}=$ fungicide application made at 50\% anthesis (Feekes 10.5.1); $\mathrm{A}+2, \mathrm{~A}+3, \mathrm{~A}+4, \mathrm{~A}+5$, and $\mathrm{A}+6=$ applications made at 2, 3, 4, 5, and 6 days after anthesis, respectively.

${ }^{\mathrm{d}}$ Diff $=$ difference between means on the raw data scale. Contrasts (e.g., differences) were constructed using LS Means based on transformation of the original data; however, for presentation, differences of original means are shown.

${ }^{\mathrm{e}} F=F$ statistic and $P=$ probability (level of significance) based on mixed model analyses of arcsine-transformed IND and log-transformed DON data.

${ }_{\mathrm{f}}^{\mathrm{f}}$ Not compared because mean DON in the untreated check was less than $0.06 \mathrm{ppm}$.

$\mathrm{g}$ Not compared because the effect of application timing was not statistically significant (see Table 1). 
after infection had occurred. The activity of a fungicide after infection, but before symptom development, is often referred to as curative effect $(19,25)$, where the fungicide is absorbed and affects mycelial growth within the plant tissue. Curative and protective activities are the physical modes of action of DMI fungicides such as tebuconazole + prothioconazole (TEBU+PROT) and metconazole (METC).

Although there is no documented report of the curative activity of TEBU+PROT and METC against FHB and DON in wheat, the curative activity of a sister active ingredient, propiconazole (4), on this disease-toxin complex has been demonstrated, as well as the curative effect of other fungicide chemistries such as cyanoacrylate (5). Following spray-inoculation of wheat spikes at 2 days after anthesis with a spore suspension of $F$. graminearum $\left(1 \times 10^{5}\right.$ spores $/ \mathrm{ml}$ ), Boyacioglu et al. (4) demonstrated that a curative application of propiconazole (Tilt 3.6 EC; Syngenta, Raleigh, NC) made 2 days after inoculation provided a greater percent control of DON $(78 \%)$ relative to the check (mean DON of $1.63 \mathrm{ppm})$ than a preventative application made 2 days before inoculation $(34 \%$ control). Very similar results were reported for kernel infection with $F$. graminearum (quantified as number of kernels infected per 200 kernels), based on a grow-out plate assay. The postinfection propiconazole treatment reduced kernel infection by 55\% relative to the check (mean infection of $18 \%$ ), while the preinfection application was ineffective. Despite the relatively low levels of infection and DON, the results from this study suggested that propiconazole acted in a curative manner to reduce $F$. graminearum infection and DON contamination. The curative effect of DMIs has also been demonstrated for other wheat diseases $(23,32)$ as well as diseases of other crops $(8,16)$.

The fact that postanthesis applications were just as effective in the naturally infected as well as the artificially inoculated experiments suggests that possible curative activity was probably not the only explanation for the observed responses. Coupled with the postulated curative effect on infected spikes, applications made "after" anthesis (for primary tillers) likely provided protection to secondary tillers which may have actually been at anthesis at the time of application, and also protected primary tillers from late (secondary) infections. The magnitude of the "late" application effect and occasional greater control with postanthesis applications (relative to anthesis application) in some studies could be due in part to differences in the relative proportion of primary and secondary tillers in a plot. If, for instance, this balance shifts in favor of secondary tillers (due to the weather-, cultivar-, and cropping practice-related factors), then postanthesis applications (using the pri- mary tillers as the reference) may perform as well as or even better than anthesis applications. If the proportion of secondary tillers is relatively high, then anthesis applications based on primary tillers will actually be treating a relatively large number of secondary spikes at preanthesis, which some studies have shown to be relatively less effective than anthesis or postanthesis applications $(38,41)$.

Differences in tiller development or the length of the anthesis window as a whole, as well as late infection, were probably the major reasons for relatively superior performance of all of the socalled postanthesis applications relative to the anthesis applications in the WO13 experiment. In that particular experiment, conditions were unseasonably cold (mean temperature of $8.5^{\circ} \mathrm{C}$ for a 48 -h period beginning at the time of treatment application) during anthesis of the primary tillers, which likely slowed down crop development and extended the anthesis window. With an extended anthesis window, postanthesis applications (based on primary tillers) likely protected more spikes at the critical anthesis growth stage (primarily on secondary tillers), while anthesis applications protected spikes on secondary tillers at preanthesis when fungicides are usually less effective against FHB. In addition, following the application of the anthesis treatments, conditions became much wetter and warmer (mean temperature of $19^{\circ} \mathrm{C}$ and $19.5 \mathrm{~mm}$ of total rainfall during the 7 days after anthesis [of the primary tillers]) than conditions at the time of anthesis application, likely favoring late infection and DON contamination $(6,7)$, and contributing to superior efficacy of the so-called postanthesis treatments.

Rainfall also likely influenced the results in the other experiment in which the $\mathrm{A}+2$ postanthesis application out-performed the anthesis application in terms of FHB index control (SC11). At South Charleston in 2011, it rained before (53 $\mathrm{mm}$ on the 2 days before), during $(33 \mathrm{~mm})$, and after anthesis $(39 \mathrm{~mm})$. Rain at the time of anthesis likely reduced fungicide efficacy, which then allowed the applications made 2 days after anthesis (when it rained only 0.51 $\mathrm{mm}$ ) to provide better FHB control than the anthesis applications. Results from a recent study conducted by Andersen et al. (1) showed that rain immediately (0 to $15 \mathrm{~min}$ ) after TEBU+PROT application may reduce the efficacy of this fungicide against FHB. Although SC11 was the only location-year that actually had natural rainfall during anthesis, it still serves to highlight the potential negative effect of rainfall on fungicide efficacy if an application is made during the rain, and to further demonstrate the value of postanthesis application when rainfall prevents effective fungicide application at anthesis. The inability to treat fields under wet, soggy conditions is not the only justification for considering a postanthesis application; reduced fungicide efficacy is another.

Table 4. Overall mean log of the response ratio, percent control, and corresponding statistics for the effect of fungicide application timings on Fusarium head blight index and deoxynivalenol (DON) in soft red winter wheat, based on data from seven field experiments conducted in Ohio and Illinois between 2011 and 2013

\begin{tabular}{|c|c|c|c|c|c|c|c|c|c|c|}
\hline \multirow[b]{2}{*}{ Response $^{c}$} & \multirow[b]{2}{*}{ Contrast $^{\mathbf{d}}$} & \multicolumn{6}{|c|}{ Effect size $^{a}$} & \multicolumn{3}{|c|}{ Mean percent control ${ }^{b}$} \\
\hline & & $\bar{L}$ & $\mathbf{S E}(\bar{L})$ & $C l_{\mathrm{L}}$ & $C l_{\mathrm{U}}$ & $Z$ & $P$ & $\bar{C}$ & $C l_{\mathrm{L}}$ & $C L_{\mathbf{U}}$ \\
\hline \multirow[t]{7}{*}{ INDEX } & A vs. CK & -0.82 & 0.113 & -1.04 & -0.60 & -7.27 & $<0.001$ & 55.85 & 44.94 & 64.60 \\
\hline & $\mathrm{A}+2$ vs. $\mathrm{CK}$ & -1.18 & 0.155 & -1.48 & -0.88 & -7.62 & $<0.001$ & 69.29 & 58.38 & 77.34 \\
\hline & $\mathrm{A}+4$ vs. $\mathrm{CK}$ & -0.96 & 0.142 & -1.24 & -0.68 & -6.76 & $<0.001$ & 61.61 & 49.32 & 70.92 \\
\hline & $\mathrm{A}+6$ vs. $\mathrm{CK}$ & -0.97 & 0.112 & -1.19 & -0.75 & -8.65 & $<0.001$ & 61.96 & 52.63 & 69.45 \\
\hline & A vs. $A+2$ & -0.36 & 0.097 & -0.55 & -0.17 & -3.74 & $<0.001$ & 30.45 & 15.84 & 42.53 \\
\hline & A vs. $A+4$ & -0.14 & 0.083 & -0.30 & 0.02 & -1.69 & 0.091 & 13.06 & -2.24 & 26.06 \\
\hline & A vs. $A+6$ & -0.15 & 0.075 & -0.30 & 0.00 & -1.98 & 0.048 & 13.83 & 0.12 & 25.66 \\
\hline \multirow[t]{7}{*}{ DON } & A vs. CK & -0.69 & 0.149 & -0.98 & -0.39 & -4.61 & $<0.001$ & 49.61 & 32.56 & 62.35 \\
\hline & $\mathrm{A}+2$ vs. $\mathrm{CK}$ & -0.77 & 0.138 & -1.04 & -0.50 & -5.58 & $<0.001$ & 53.58 & 39.18 & 64.56 \\
\hline & $\mathrm{A}+4$ vs. $\mathrm{CK}$ & -0.74 & 0.117 & -0.97 & -0.51 & -6.34 & $<0.001$ & 52.43 & 40.14 & 62.20 \\
\hline & $\mathrm{A}+6$ vs. $\mathrm{CK}$ & -0.65 & 0.101 & -0.85 & -0.46 & -6.45 & $<0.001$ & 48.02 & 36.57 & 57.40 \\
\hline & A vs. A+2 & -0.08 & 0.076 & -0.23 & 0.07 & -1.07 & 0.284 & 7.87 & -7.03 & 20.69 \\
\hline & A vs. $A+4$ & -0.06 & 0.079 & -0.21 & 0.09 & -0.72 & 0.469 & 5.59 & -10.34 & 19.22 \\
\hline & $A$ vs. $A+6$ & 0.03 & 0.086 & -0.14 & 0.20 & 0.36 & 0.718 & -3.17 & -22.23 & 12.92 \\
\hline
\end{tabular}

a $\bar{L}=$ mean $\log$ of the response ratio between each application timing and the check and between postanthesis and anthesis applications; SE $(\bar{L})=$ standard error of $\bar{L} ; Z=$ standard normal test statistic; $P=$ significance level; $C I_{\mathrm{U}}$ and $C I_{\mathrm{L}}=$ upper and lower limits of the $95 \%$ confidence interval around $\bar{L}$.

b $\bar{C}=$ mean percent control was estimated from $\bar{L}$ as $\bar{C}=[1-\exp (\bar{L})] \cdot 100 ; C I_{\mathrm{U}}$ and $C I_{\mathrm{L}}=$ upper and lower limits of the $95 \%$ confidence interval around $\bar{C}$.

${ }^{c}$ Fusarium head blight index (proportion of diseased spikelets per spike) and deoxynivalenol (DON) from harvested grain (ppm).

${ }^{\mathrm{d}}$ Fungicide applications made at anthesis $(\mathrm{A})$ or at $2(\mathrm{~A}+2), 4(\mathrm{~A}+4)$, or $6(\mathrm{~A}+6)$ days after anthesis. $\mathrm{CK}=$ untreated check. 
Although there have been multiple previous studies evaluating the effects of pre- and postanthesis fungicide applications on FHB and DON $(14,38,41)$, none of those studies evaluated the effects of a single fungicide application within the 1-week postanthesis window evaluated in this study. For instance, while Yoshida et al. (41) determined that a fungicide application at 20 days after anthesis effectively controlled mycotoxin levels in Japan, this recommendation is not useful in SRWW production areas in the Midwest due to preharvest interval (PHI) restrictions. The time interval between applying a fungicide at 20 days after anthesis and harvest (approximately 21 days in SRWW growing regions) would not meet the legally required PHI for TEBU+PROT or METC (30 days). In addition, TEBU+PROT or METC were not evaluated in any of the previous studies, nor were the studies conducted in the U.S. Midwest. Since fungicide effects on FHB and DON have been shown to be affected by fungicide active ingredients, weather conditions, growing regions, and wheat market classes (30), it is important to take these factors into consideration when evaluating postanthesis fungicide applications.

All wheat growing regions and their associated wheat class have their own unique set of growing conditions and environmental variables that need to be addressed when considering management decisions. In the U.S. Midwest, fungicide spray recommendations for FHB management are based on applications at anthesis; however, ideal conditions for FHB development are not often congruent with these recommended fungicide applications. While it is important to continue to actively monitor anthesis dates, our study showed that fungicides are still able to adequately control FHB and DON when applied up to 6 days after 50\% early anthesis. This implies that the fungicide application window for effective FHB control could potentially be extended, which would allow producers the flexibility of applying fungicide treatments after rain events. Under the conditions of this study, the applications made 6 days after $50 \%$ anthesis were within the preharvest interval. However, while this study presents consistently lower IND and DON in postanthesis fungicide applications relative to untreated controls in SRWW in Ohio and Illinois, further research is still needed to determine if these effects will be consistent across wheat classes and growing regions in the United States, and whether postanthesis applications will violate the legal preharvest interval in other locations.

\section{Acknowledgments}

This investigation is based upon work supported, in part, by the U.S. Department of Agriculture through the U.S. Wheat \& Barley Scab Initiative (Agreement no. 59-0206-9-071) and the Ohio Small Grains Marketing Program. Any opinions, findings, conclusions, or recommendations expressed in this publication are those of the authors and do not necessarily reflect the view of the U.S. Department of Agriculture. Salaries and research support for D. L. D'Angelo, P. A. Paul, and L. V. Madden were provided by state and federal funds to the Ohio Agricultural Research and Development Center. Special thanks to M. Wallhead, K. Davies, W. Bardall, R. Barry, J. Heller, J. Davlin, and J. Engle for assisting with establishment, maintenance, and harvest of research plots and treatment application. Special thanks for D. Hershman from the University of Kentucky for reviewing an earlier version of this manuscript.

\section{Literature Cited}

1. Andersen, K. F., Morris, L., Derksen, R.C., Madden, L.V., and Paul, P. A. 2014. Rainfastness of prothioconazole + tebuconazole for Fusarium head blight and deoxynivalenol management in soft red winter wheat. Plant Dis. 98:1398-1406.

2. Bai, G., and Shaner, G. 1994. Scab of wheat: Prospects for control. Plant Dis. 78:760-766.

3. Beyer, M., Klix, M., Klink, H., and Verrett, J.-A. 2006. Quantifying the effects of previous crop, tillage, cultivar and triazole fungicides on the deoxynivalenol content of wheat grain-a review. J. Plant Dis. Prot. 113:241246.

4. Boyacioglu, D., Hettiarachchy, N. S., and Stack, R. W. 1992. Effect of three systemic fungicides on deoxynivalenol (vomitoxin) production by Fusarium graminearum in wheat. Can. J. Plant Sci. 72:93-101.

5. Chen, Y., Wang, W. X., Zhang, A. F., Gu, C.-Y., Zhau, M. G., and Gao, T. C. 2011. Activity of the fungicide JS399-19 against Fusarium head blight of wheat and the risk of resistance. Agric. Sci. China 10:1906-1913.

6. Cowger, C., Patton-Özkurt, J., Brown-Guedira, G., and Perugini, L. 2009. Post-anthesis moisture increased Fusarium head blight and deoxynivalenol levels in North Carolina winter wheat. Phytopathology 99:320-327.

7. Culler, M. D., Miller-Garvin, J. E., and Dill-Macky, R. 2007. Effect of extended irrigation and host resistance on deoxynivalenol accumulation in Fusarium-infected wheat. Plant Dis. 91:1464-1472.

8. Dahmen, H., and Straub, T. 1992. Protective, curative, and eradicant activity of difenoconazole against Venturia inaequalis, Cercospora arachidicola, and Alternaria solani. Plant Dis. 76:774-777.

9. De Wolf, E., Madden, L., and Lipps, P. 2003. Risk assessment models for wheat Fusarium head blight epidemics based on within season weather data. Phytopathology 93:428-435.

10. Del Ponte, E. M., Fernandes, J. M. C., and Bergstrom, G. C. 2007. Influence of growth stage on Fusarium head blight and deoxynivalenol production in wheat. J. Phytopathol. 155:577-581.

11. Dexter, J. E., Clear, R. M., and Preston, K. R. 1996. Fusarium head blight: Effect on the milling and baking of some Canadian wheats. Cereal Chem. 73:695-701.

12. Diekman, M. A., and Green, M. L. 1992. Mycotoxins and reproduction in domestic livestock. J. Anim. Sci. 70:1615-1627.

13. Dufault, N. S., De Wolf, E. D., Lipps, P. E., and Madden, L. V. 2006. Role of temperature and moisture in the production and maturation of Gibberella zeae perithecia. Plant Dis. 90:637-644.

14. Edwards, S. G., and Godley, N. P. 2010. Reduction of Fusarium head blight and deoxynivalenol in wheat with early fungicide applications of prothioconazole. Food Addit. Contam. Part A 27:629-635.

15. Gilbert, J., and Tekauz, A. 2000. Review: Recent developments in research on Fusarium head blight of wheat in Canada. Can. J. Plant Pathol. 22:1-8.

16. Godoy, C. V., and Canteri, M. G. 2004. Efeitos protetor, curativo e erradicante de fungicidas no controle da ferrugem da soja causada por Phakopsora pachyrhizi, em casa de vegetação. Fitopatol. Bras. 29:97-101.

17. Haidukowski, M., Pascale, M., Perrone, G., Pancaldi, D., Campagna, C., and Visconti, A. 2005. Effect of fungicides on the development of Fusarium head blight, yield and deoxynivalenol accumulation in wheat inoculated under field conditions with Fusarium graminearum and Fusarium culmorum. J. Sci. Food Agric. 85:191.

18. Hart, L. P., Pestka, J. J., and Liu, M. T. 1984. Effect of kernel development and wet periods on production of deoxynivalenol in wheat infected with Gibberella zeae. Phytopathology 74:1415-1418.

19. Ivic, D. 2010. Curative and eradicative effects of fungicides. Pages 3-22 in: Fungicides. O. Carisse, ed. InTech. DOI:10.5772/555.

20. Lacey, J., Bateman, G. L., and Mirocha, C. J. 1999. Effects of infection time and moisture on development of ear blight and deoxynivalenol production by Fusarium spp. in wheat. Ann. Appl. Biol. 134:277-283.

21. Littell, R. C., Milliken, G. A., Stroup, W. W., Wolfinger, R. D., and Schabenberger, O. 2006. SAS for Mixed Models, 2nd ed. SAS Institute Inc.,Cary, NC.

22. Lori, G. A., Sisterna, S. J., Rizzo, I., and Chidichimo, H. 2009. Fusarium head blight in wheat: Impact of tillage and other agronomic practices under natural infection. Crop Prot. 28:495-502.

23. Mangin-Peyrard, M., and Pepin, R. 1996. Encasement of Erysiphe graminis haustoria after treatment with bromuconazole. Pestic. Sci. 46:121-130.

24. McMullen, M., Jones, R., and Gallenberg, D. 1997. Scab of wheat and barley: A re-emerging disease of devestating impact. Plant Dis. 81:13401348 .

25. Mueller, D. S., and Bradley, C. A. 2008. Field crop fungicide for the north central United States. North Central Integrated Pest Management Center, Urbana-Champaign, IL.

26. Parry, D. W., Jenkinson, P., and McLeod, L. 1995. Fusarium ear blight (scab) in small grain cereals-a review. Plant Pathol. 44:207-238.

27. Paul, P. A., El-Allaf, S. M., Lipps, P. E., and Madden, L. V. 2004. Rain splash dispersal of Gibberella zeae within wheat canopies in Ohio. Phytopathology 94:1342-1349.

28. Paul, P. A., El-Allaf, S. M., Lipps, P. E., and Madden, L. V. 2005. Relationships between incidence and severity of Fusarium head blight on winter wheat in Ohio. Phytopathology 95:1049-1060.

29. Paul, P., Lipps, P., Hershman, D., McMullen, M., Draper, M., and Madden, L. 2007. A quantitative review of tebuconazole effect on Fusarium head blight and deoxynivalenol content in wheat. Phytopathology 97:211-220.

30. Paul, P., Lipps, P., Hershman, D., McMullen, M., Draper, M., and Madden, L. 2008. Efficacy of triazole-based fungicides for Fusarium head blight and deoxynivalenol control in wheat: A multivariate meta-analysis. Phytopathology 98:999-1011.

31. Paul, P., Lipps, P., and Madden, L. 2005. Relationship between Fusarium head blight intensity and deoxynivalenol accumulation in harvested wheat grain. Phytopathology 95:1225-1236.

32. Schöfl, U. A., and Zinkernagel, V. 1997. A test method based on microscopic assessments to determine curative and protectant fungicide properties against Septoria tritici. Plant Pathol. 46:545-556.

33. Shah, D. A., Molineros, J. E., Paul, P. A., Willyerd, K. T., Madden, L. V., and DeWolf, E. D. 2013. Predicting Fusarium head blight epidemics with weather-driven pre- and post-anthesis logistic regression models. Phytopathology 103:906-1019.

34. Stack, R. W., and McMullen, M. P. 1998. A visual scale to estimate severity of Fusarium head blight in wheat. NDSU Extension Service: Small Grains Publications. Online Publication/PP-1095. 
35. Sutton, J. C. 1982. Epidemiology of wheat head blight and maize ear rot caused by Fusarium graminearum. Can. J. Plant Pathol. 4:195-209.

36. Tuite, J. F. 1969. Plant pathological methods: Fungi and bacteria. Burgess Publishing Company, Minneapolis, MN.

37. Wegulo, S. N., Bockus, W. W., Hernandez Nopsa, J., De Wolf, E. D., Eskridge, K. M., Peiris, K. H. S., and Dowell, F. E. 2011. Effects of integrating cultivar resistance and fungicide application on Fusarium head blight and deoxynivalenol in winter wheat. Plant Dis. 95:554-560.

38. Wiersma, J. J., and Motteberg, C. D. 2005. Evaluation of five fungicide application timings for control of leaf-spot diseases and Fusarium head blight in hard red spring wheat. Can. J. Plant Pathol. 27:25-37.

39. Willyerd, K. T., Li, C., and Madden, L. V. 2012. Efficacy and stability of integrating fungicide and cultivar resistance to manage Fusarium head blight and deoxynivalenol in wheat. Plant Dis. 96:957-967.

40. Yoshida, M., Kawada, N., and Nakajima, T. 2007. Effect of infection timing on Fusarium head blight and mycotoxin accumulation in open- and closedflowering barley. Phytopathology 97:1054-1062.

41. Yoshida, M., Nakajima, T., Tomimura, K., Suzuki, F., Arai, M., and Miyasaka, A. 2012. Effect of the timing of fungicide application on Fusarium head bligh and mycotoxin accumulation in wheat. Plant Dis. 96:845-851. 